\title{
U.S. CARBON TAX SCENARIOS AND BIOENERGY
}

\author{
RONALD D. SANDS \\ U.S. Department of Agriculture, \\ Economic Research Service \\ Washington, D.C., USA \\ RSANDS@ers.usda.gov \\ Received 1 November 2017 \\ Revised 3 January 2018 \\ Accepted 3 January 2018 \\ Published 20 March 2018
}

\begin{abstract}
This paper documents application of the Future Agricultural Resources Model (FARM) to stylized carbon tax scenarios specified by the Stanford Energy Modeling Forum (EMF). Model results show that the method of tax revenue recycling makes a difference. Either labor-tax, or capital-tax, recycling can reduce the welfare cost of a carbon tax policy relative to lump sum recycling. Of the two tax recycling options, reducing capital taxes provides the greater reduction in welfare costs. However, carbon tax revenues decline with stringent carbon dioxide $\left(\mathrm{CO}_{2}\right)$ emission targets and the availability of a negative-emissions technology such as bio-electricity with $\mathrm{CO}_{2}$ capture and storage (BECCS). As BECCS expands, net carbon tax revenues peak and decline due to an offsetting subsidy for carbon sequestration, limiting the potential for labor- or capital-tax recycling to reduce welfare costs of a climate policy.
\end{abstract}

Keywords: Bio-electricity; carbon tax; climate policy; greenhouse gas; negative emissions; revenue recycling.

\section{Introduction}

The first meeting of Stanford Energy Modeling Forum study 32 (EMF-32) took place during October 2014 in Washington, D.C. Over the course of this study, "U.S. Carbon Tax Scenarios", three rounds of scenarios and meetings addressed the following questions:

- If the United States adopts an economy-wide carbon tax, how do the environmental and economic outcomes depend on how the government uses the revenue?

- How do the outcomes of a U.S. carbon tax depend on the initial tax rate and the rate at which the tax escalates?

This is an Open Access article published by World Scientific Publishing Company. It is distributed under the terms of the Creative Commons Attribution 4.0 (CC-BY) License. Further distribution of this work is permitted, provided the original work is properly cited. 
Table 1. Scenarios discussed in this paper.

\begin{tabular}{|c|c|c|}
\hline Scenario abbreviation & Scenario description & Carbon tax recycling options \\
\hline Reference & $\begin{array}{l}\mathrm{CO}_{2} \text { emissions from fossil fuels from } 2010 \\
\text { through } 2050 \text { without climate policy }\end{array}$ & \\
\hline$\$ 25 @ 5 \% \mathrm{C}$ tax & $\begin{array}{l}\text { Carbon tax of } \$ 25 / \mathrm{tCO}_{2} \text { beginning in } \\
2020 \text {, increasing at } 5 \% \text { per year }\end{array}$ & Lump sum, labor, capital \\
\hline$\$ 50 @ 5 \% \mathrm{C}$ tax & $\begin{array}{c}\text { Carbon tax of } \$ 50 / \mathrm{tCO}_{2} \text { beginning in } \\
2020 \text {, increasing at } 5 \% \text { per year }\end{array}$ & Lump sum, labor, capital \\
\hline$\$ 25 @ 1 \% \mathrm{C}$ tax & $\begin{array}{c}\text { Carbon tax of } \$ 25 / \mathrm{tCO}_{2} \text { beginning in } \\
2020 \text {, increasing at } 1 \% \text { per year }\end{array}$ & Lump sum, labor, capital \\
\hline$\$ 50 @ 1 \% \mathrm{C}$ tax & $\begin{array}{c}\text { Carbon tax of } \$ 50 / \mathrm{tCO}_{2} \text { beginning in } \\
2020 \text {, increasing at } 1 \% \text { per year }\end{array}$ & Lump sum, labor, capital \\
\hline $76 \%$ reduction (no BECCS) ${ }^{\mathrm{a}}$ & $\begin{array}{r}\mathrm{CO}_{2} \text { emissions reduced } 76 \% \text { from } 2005 \\
\text { levels by } 2050 \text {; CCS is available for } \\
\text { fossil fuels but not for bio-electricity }\end{array}$ & Lump sum \\
\hline $76 \%$ reduction with BECCS & $\begin{array}{l}\mathrm{CO}_{2} \text { emissions reduced } 76 \% \text { from } 2005 \\
\text { levels by } 2050 \text {; CCS is available for } \\
\text { all electricity generation technologies, } \\
\text { including bio-electricity }\end{array}$ & Lump sum \\
\hline
\end{tabular}

Note: ${ }^{\text {a The }} 76 \%$ reduction scenarios are labeled as $80 \%$ reduction scenarios in the EMF-32 protocol, with an $80 \%$ reduction in net greenhouse gas emissions. Some of the required reductions are offset by a land and forestry sink, so that $\mathrm{CO}_{2}$ emissions need only be reduced by $76 \%$ relative to 2005 .

Table 1 lists the scenarios used for this paper. The first scenario is a reference scenario of U.S. carbon dioxide $\left(\mathrm{CO}_{2}\right)$ emissions from fossil fuel combustion from 2010 through 2050. All other scenarios will be compared to the reference in terms of emissions reductions and policy cost. The next four scenarios use an exogenous carbon price, starting in 2020, to cover variation in the initial carbon price and rate of increase over time. The starting price is either $\$ 25$ or $\$ 50$ per metric ton of $\mathrm{CO}_{2}$, with annual increases of $1 \%$ or $5 \%$. Each of these four scenarios has variations to cover three types of carbon tax revenue recycling: lump sum to consumers, reduction in labor tax rates, and reduction in capital tax rates. The primary model output used to compare tax recycling options is consumer welfare, measured as equivalent variation.

Instead of an exogenous carbon price path, the next scenario specifies an exogenous time path of $\mathrm{CO}_{2}$ emissions, and the carbon price becomes endogenous. This is a deep de-carbonization scenario with emissions declining steadily after 2020 to reach a level $76 \%$ below 2005 emissions by 2050. In this scenario, we allow electricity generation from fossil fuels to use carbon dioxide capture and storage (CCS) if the carbon price is high enough to cover the cost of CCS. The option to use CCS limits the carbon tax and cost needed to meet an ambitious $\mathrm{CO}_{2}$ emissions target.

The final scenario, the modeler's choice scenario, also has a $76 \%$ emissions reduction target, but allows CCS to be used with bio-electricity (BECCS) as well as with electricity generation using fossil fuels. The possibility of bio-electricity combined with $\mathrm{CCS}$ creates a technology with the potential for negative $\mathrm{CO}_{2}$ emissions, 


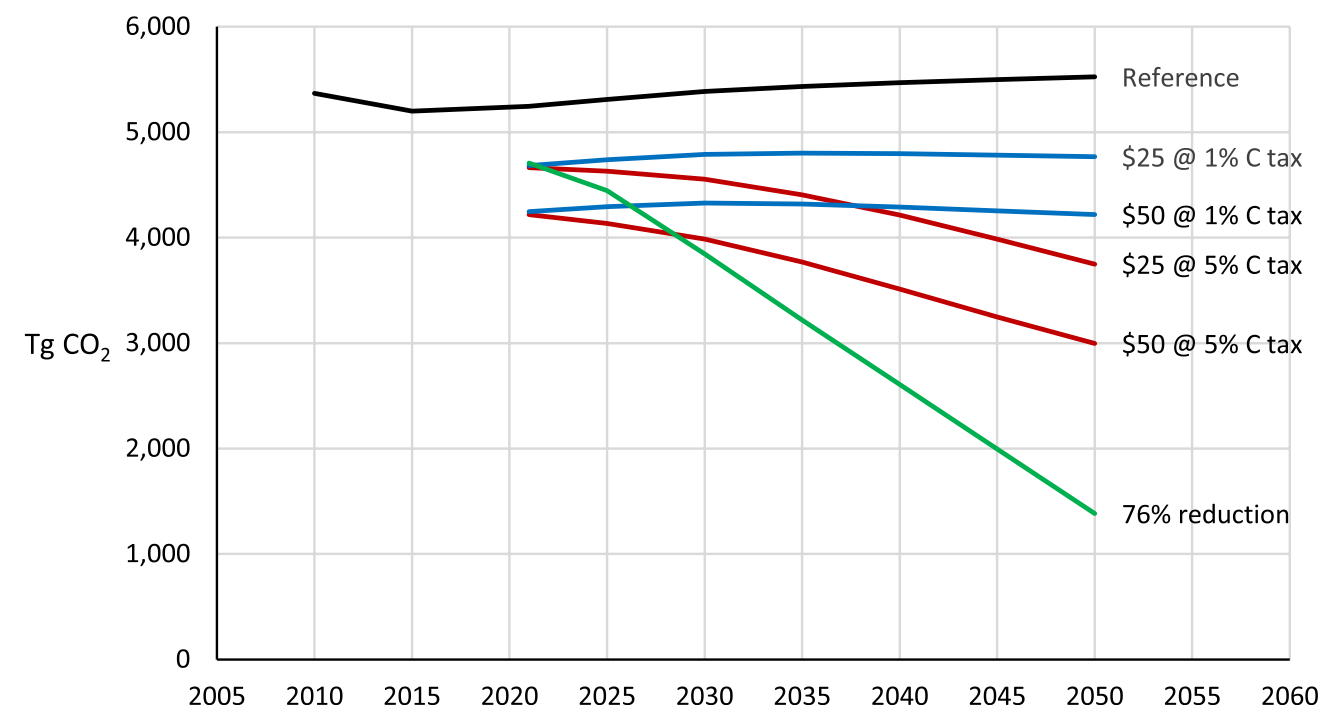

Note: $\mathrm{Tg} \mathrm{CO}_{2}=$ teragrams $\mathrm{CO}_{2}=$ million metric tons of $\mathrm{CO}_{2}$.

Figure 1. U.S. $\mathrm{CO}_{2}$ emissions pathways

but the economics of this technology are unlike any other mitigation technology, with joint products of electricity and net carbon sequestration.

It turns out that the option to recycle carbon tax revenue by reducing labor taxes or capital taxes can reduce the cost of $\mathrm{CO}_{2}$ mitigation in scenarios with an exogenous

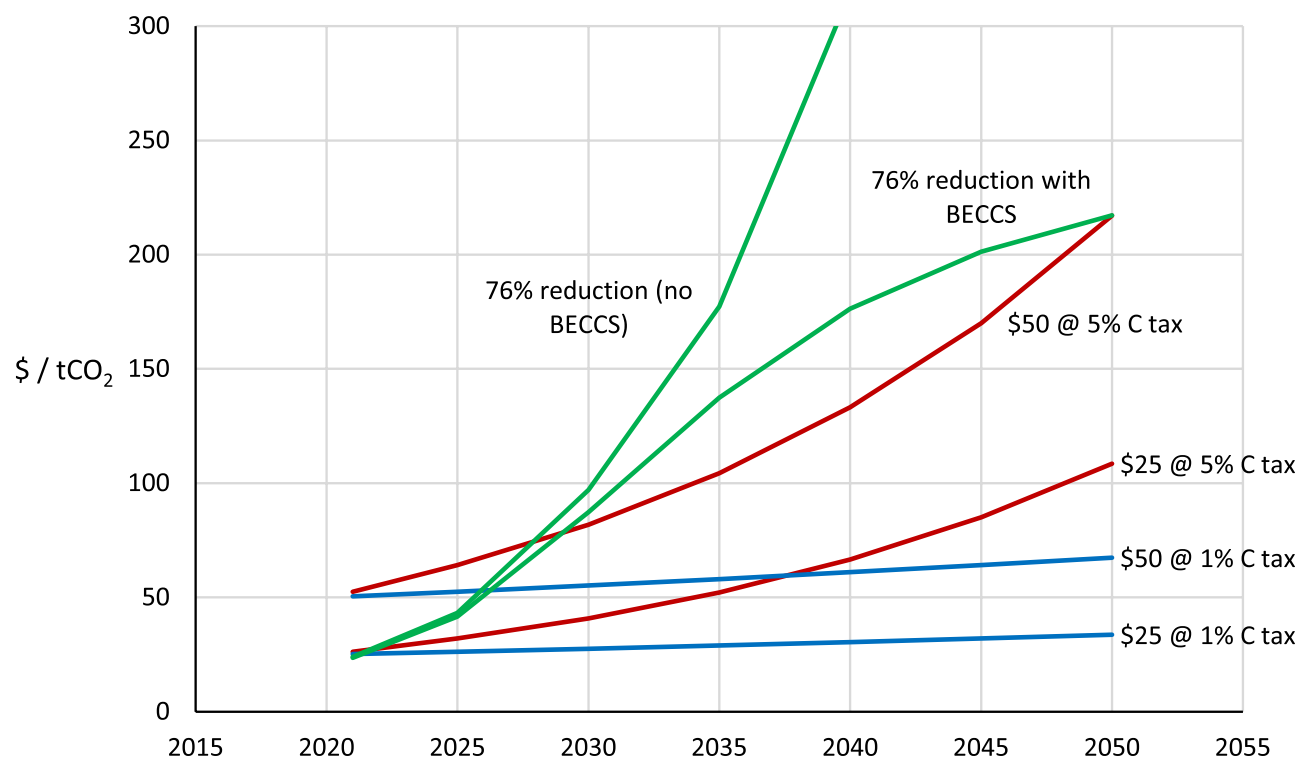

Figure 2. U.S. $\mathrm{CO}_{2}$ prices by emissions pathway 
carbon price path. However, with BECCS, revenues from a carbon policy reach a peak and then decline as a subsidy for sequestration offsets carbon tax revenues. The deep de-carbonization scenarios reduce $\mathrm{CO}_{2}$ emissions $76 \%$ by 2050 , relative to $2005 \mathrm{CO}_{2}$ emissions of $5,753 \mathrm{Tg} \mathrm{CO}_{2}$.

$\mathrm{CO}_{2}$ emissions pathways for the reference and climate policy scenarios are displayed in Fig. 1. ${ }^{1}$ The four exogenous-carbon-tax scenarios provide a wide range of emissions reductions by 2050 , up to $48 \%$ below 2005 emissions in the scenario with a $\$ 50$ tax in 2020 increasing at 5\% per year.

$\mathrm{CO}_{2}$ prices for each scenario are shown in Fig. 2. Exogenous time series in Fig. 1 become endogenous in Fig. 2, and vice versa. The 76\% emissions reduction pathway in Fig. 1 is exogenous, but the corresponding $\mathrm{CO}_{2}$ price paths in Fig. 2 are endogenous and vary by the presence or absence of BECCS.

\section{Economic Framework}

We use the Future Agricultural Resources Model (FARM), a global computablegeneral-equilibrium (CGE) model developed and maintained at USDA's Economic Research Service. The U.S. is one of 13 world regions simulated in 5-year steps from 2011 to 2051. The first version of FARM was constructed in the early 1990s by Roy Darwin and others at ERS (Darwin et al., 1995). By partitioning land into land classes, this model provided a unique capability among CGE models to simulate land use on a global scale. Early versions of the FARM model were used to simulate the impact of a changed climate on global land use, agricultural production, and international trade.

Data requirements include a base-year social accounting matrix from the Global Trade Analysis Project (GTAP) at Purdue University, energy balances from the International Energy Agency (IEA), land use from the Food and Agriculture Organization (FAO) of the United Nations, and agricultural production from FAO. GTAP data provide social accounting matrices for 140 world regions and 57 production sectors (Lanz and Rutherford, 2016). These data are then aggregated to 13 world regions, corresponding to region definitions of the Agricultural Model Intercomparison and Improvement Project (AgMIP), and 38 production sectors. The production sectors retain all GTAP information related to primary agriculture, food processing, energy transformation, energy-intensive industries, and transportation.

GTAP datasets are constructed to maintain consistency between energy values in the GTAP social accounting matrix and energy quantities from energy balances distributed by IEA. This provides energy values consistent with the law of one price for each energy carrier: within each world region, all consumers of energy pay the same price net of tax and transport margins. The GTAP data distribution includes supplemental energy quantity data aggregated from detailed IEA energy balances, which

\footnotetext{
${ }^{1}$ The FARM model operates in five-year time steps from 2011 through 2051, with the start year matching that of the benchmark social accounting matrix from the Global Trade Analysis Project (GTAP). Carbon tax policies begin in 2021, the third model time step.
} 
provide sufficient energy information for calculating $\mathrm{CO}_{2}$ emissions from energy combustion.

Further data processing expands the number of production sectors: the single electricity production sector in GTAP is expanded to include nine electricity generating technologies; household transportation is removed from final demand to create a new transportation services sector; and household energy consumption is also removed from final demand to create a new energy services sector. Dedicated biomass production is introduced as a new field crop, which is then combusted to generate electricity. Biomass therefore becomes a link between agricultural and energy systems. Further model background is available in Sands et al. (2014a, 2017).

The FARM model has the following features for running EMF-32 scenarios:

- GTAP-9 social accounting matrix (SAM) with 2011 base year.

- Energy accounting throughout the U.S. economy, from primary energy to final energy consumption.

- Labor-leisure tradeoff in utility function.

- Calculation of equivalent variation for any policy scenario relative to the reference scenario.

- Option to keep real government expenditure the same in the reference and policy scenarios.

- Option to tax final energy consumption based on carbon content of fuels.

- Options for recycling carbon tax revenue.

- Representation of specific electricity generation technologies, including bio-electricity with and without CCS.

- Five-year time steps from 2011 to 2051, interpolated to five-year time steps from 2010 to 2050 for EMF reporting.

- Capital accumulation at each time step.

- Exogenous technical change over time.

- Land competition among forests, pasture, crops, and a dedicated energy crop (switchgrass).

The FARM model is recursive dynamic — essentially a sequence of static equilibria with capital stock accumulating endogenously over time. Population and labor productivity increase to drive economic growth.

Savings is based on the Extended Linear Expenditure System, with saving a fixed value-share of consumer expenditure. Therefore, investment is a fixed fraction of total expenditure, and a reduced purchase price for capital goods allows more capital to be purchased and accumulate over time. Capital stock is fixed within each time step, determined by the previous period capital stock and previous period investment.

The tax system in the GTAP social accounting matrix includes indirect taxes; for Federal, state, and local combined; but does not include direct taxes on capital and labor income. Direct taxes are not included because the GTAP data have a single representative agent in each world region that represents both the consumer and 
government, and direct taxes cancel. Since direct taxes are the focus of many EMF-32 scenarios, direct taxes were introduced into the U.S. region of the model. ${ }^{2}$

International capital flows, for all time steps, are fixed at base-year (2011) values. Each world region has its own numeraire, and real exchange rates vary over time. The biomass crop does not trade among world regions, but all other products trade among regions.

The economics of BECCS is complex relative to other $\mathrm{CO}_{2}$ mitigation technologies, with rents accruing to owners of agricultural land and owners of the carbon sequestration resource. Further, a BECCS activity has joint products of electricity and carbon sequestration.

A CGE model is essentially a system of nonlinear equations with the same number of equations as variables. Three types of equations appear in all CGE models: market clearing, income balance, and zero-profit (efficiency) conditions. Market clearing equations are paired with prices; income balance equations are paired with revenue; and zero-profit conditions are paired with the scale (gross output) of production activities. Because all variables that describe an economy are endogenous in a CGE model, it is difficult to isolate the behavior of any component. For example, biomass supply curves are implicit and cannot be written in closed form. ${ }^{3}$

Applying this analogy to a BECCS activity, if we consider the price of $\mathrm{CO}_{2}$ and the price of electricity as exogenous, we can construct a list of variables and paired equations, as in Table 2. Other key parameters are the efficiency of converting biomass to electricity, switchgrass yield, energy content of switchgrass, and the quantity of $\mathrm{CO}_{2}$ emitted per ton of switchgrass combusted.

Table 2. Simplified representation of a BECCS activity.

\begin{tabular}{ll}
\hline Variables & \multicolumn{1}{c}{ Paired equations } \\
\hline Quantity of CCS supplied & Supply curve for CCS \\
Quantity of CCS demanded & Demand for CCS from BECCS \\
Price of CCS resource & Market clearing for CCS resource \\
Quantity of cropland supplied & Supply curve for cropland \\
Quantity of cropland demanded & Demand for cropland from BECCS \\
Price of cropland & Market clearing for cropland \\
Scale of operation for BECCS & BECCS zero-profit condition \\
$\quad$ the quantity of electricity generated) & \\
\hline
\end{tabular}

\footnotetext{
${ }^{2}$ The GTAP SAM includes "factor taxes", but the labor tax includes only social security taxes of $15 \%$ covering employee and employer contributions. Factor taxes were adjusted to increase the average labor tax rate to $27 \%$; the tax rate on capital was increased to $15 \%$.

${ }^{3}$ One can isolate components of a CGE model by setting some variables exogenously and ignoring the corresponding equation. This becomes a smaller, partial-equilibrium model. Using the biomass supply example, one can set the price of biomass exogenously and ignore the biomass market clearing equation. Repeating this for varying biomass prices allows one to obtain points along the biomass supply curve.
} 
The zero-profit condition for BECCS states that revenues from its joint products, from electricity sales and carbon sequestration, equal total cost of production. If the $\mathrm{CO}_{2}$ price is less than the cost of sequestration, then BECCS operates as bio-electricity without sequestration. See Sands et al. (2014b) for an example of how BECCS operates within a CGE model.

\section{Tax Recycling Scenarios}

Each of the four fixed-carbon-tax scenarios was run with three types of tax revenue recycling: lump sum to a representative consumer; an equivalent reduction in direct taxes on labor; and an equivalent reduction on capital taxes. The primary model output to view the impact of labor tax or capital tax recycling is equivalent variation based on the representative consumer's utility function, and is generally comparable to the loss in real consumption. Figure 3 provides time series plots of equivalent variation for three fixed-carbon-tax scenarios (the fourth was excluded for visual clarity) in units of billion dollars, with welfare losses as negative numbers. Equivalent variation for lump sum recycling is shown as solid lines, while the corresponding labor-tax-recycling scenario is shown as dashed lines of the same color.

Equivalent variation is negative for all scenarios in Fig. 3, but a lower cost is achieved with labor tax recycling relative to lump sum recycling. ${ }^{4}$ The pattern for each

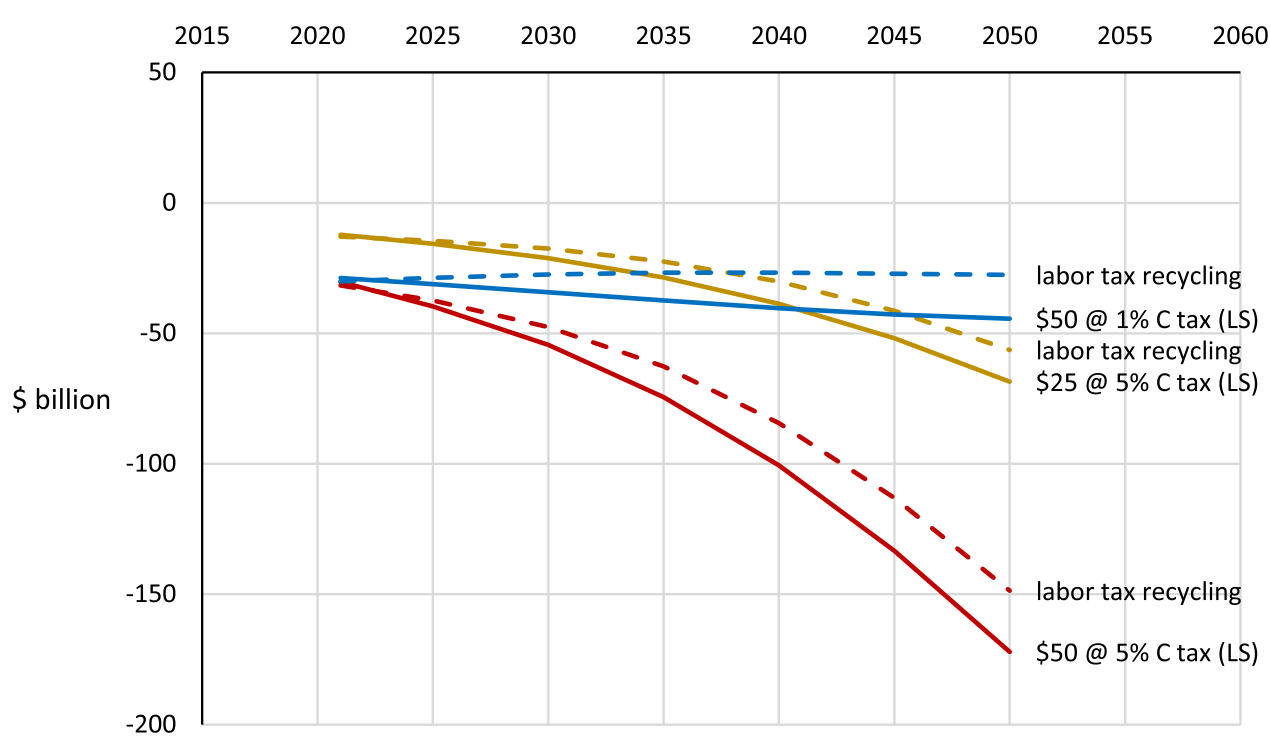

Notes: $\mathrm{LS}=$ lump sum recycling of carbon tax revenues.

Dashed lines for "labor tax recycling" correspond to the carbon tax scenario with the same color.

Figure 3. Revenue recycling through labor tax (equivalent variation)

\footnotetext{
${ }^{4}$ The reduction in welfare costs with labor-tax recycling is a result of the labor-leisure tradeoff. Labor is taxed but leisure is not. A reduction in the labor tax rate increases the quantity of labor supplied.
} 


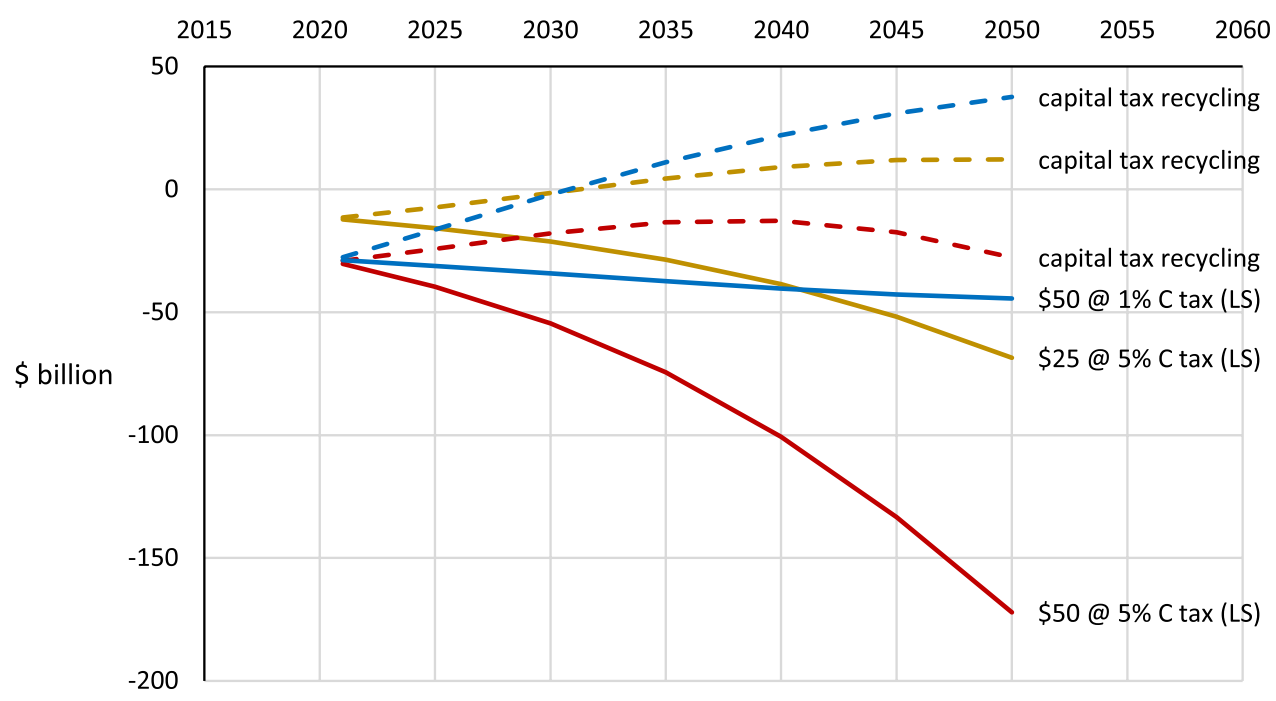

Notes: LS = lump sum recycling of carbon tax revenues.

Dashed lines for "capital tax recycling" correspond to the carbon tax scenario with the same color.

Figure 4. Revenue recycling through capital tax (equivalent variation)

carbon-tax scenario is the same, with the difference in welfare starting small and increasing over time.

Figure 4 provides the same type of plot for capital tax recycling. The solid lines in Fig. 4 are the same as in Fig. 3, and they represent the welfare loss for each carbon-tax scenario with lump sum recycling. Again, we have a similar pattern: the welfare loss is reduced through capital-tax recycling, with the welfare difference starting small and increasing over time. However, the change in welfare is larger with capital tax recycling relative to lump sum recycling. In two cases, there is a welfare gain in later time periods.

The logic behind welfare improvements with capital-tax recycling is simple: investment is a fixed fraction of total expenditure, and a reduced purchase price for capital goods allows more capital to be purchased each time step. Capital stock is fixed within each time step, and the increase in capital appears in the next time step. Therefore, the effect of a reduction in capital taxes does not appear until the second time step (2025). The capital stock continues to grow over time, relative to capital stock in the reference scenario.

\section{Deep De-Carbonization Scenarios}

From Figs. 3 and 4, one might conclude that welfare improvements due to labor-tax or capital-tax recycling will continue over time and will scale with the stringency of the climate policy. However, this is not true in general: this assumes that carbon-tax revenues scale with stringency of a climate policy.

If CCS becomes widely available, then bio-electricity has a unique advantage over all other electricity-generating technologies: bioelectricity combined with CCS can 
provide negative emissions of $\mathrm{CO}_{2}$. In this case, $\mathrm{CO}_{2}$ is removed from the atmosphere by an energy crop; the crop is combusted to generate steam to drive electric turbines; the $\mathrm{CO}_{2}$ released from biomass combustion is captured; and then the $\mathrm{CO}_{2}$ is pressurized and stored underground.

Many studies that limit long-term global average surface temperature increases to less than $2^{\circ} \mathrm{C}$, use large-scale bioenergy combined with CCS (e.g., Edmonds et al., 2013). BECCS is part of the technology mix for nearly all global integrated assessment models running scenarios with net $\mathrm{CO}_{2}$ emissions approaching zero toward the end of this century. Economical operation of $\mathrm{CCS}$ requires a $\mathrm{CO}_{2}$ price high enough to cover the cost of CCS installation and operation.

For most scenarios in Fig. 5, tax revenue increases with the carbon tax. The one exception is the $76 \%$ reduction scenario with BECCS. In this case, carbon tax revenues peak and then decline as carbon sequestration increases through BECCS. The reason for the decline is that a subsidy must be paid to BECCS operators for each ton of carbon sequestered, at the prevailing carbon price. If the scale of BECCS becomes large relative to other mitigation technologies, then net $\mathrm{CO}_{2}$ emissions could become negative for the entire economy. In this case, the government pays a net subsidy instead of receiving tax revenue. The scale of BECCS is limited, however, by the amount of land needed to grow an energy crop (e.g., switchgrass) and competition with land used to grow crops. Carbon tax revenues, as a percent of gross domestic product (GDP), are shown in Table 3 for each scenario. Scenarios with a $1 \%$ per year increase in the carbon tax have a relatively constant ratio of revenue to GDP. Scenarios with a 5\% per year increase in the carbon tax have an increasing ratio of revenue to GDP.

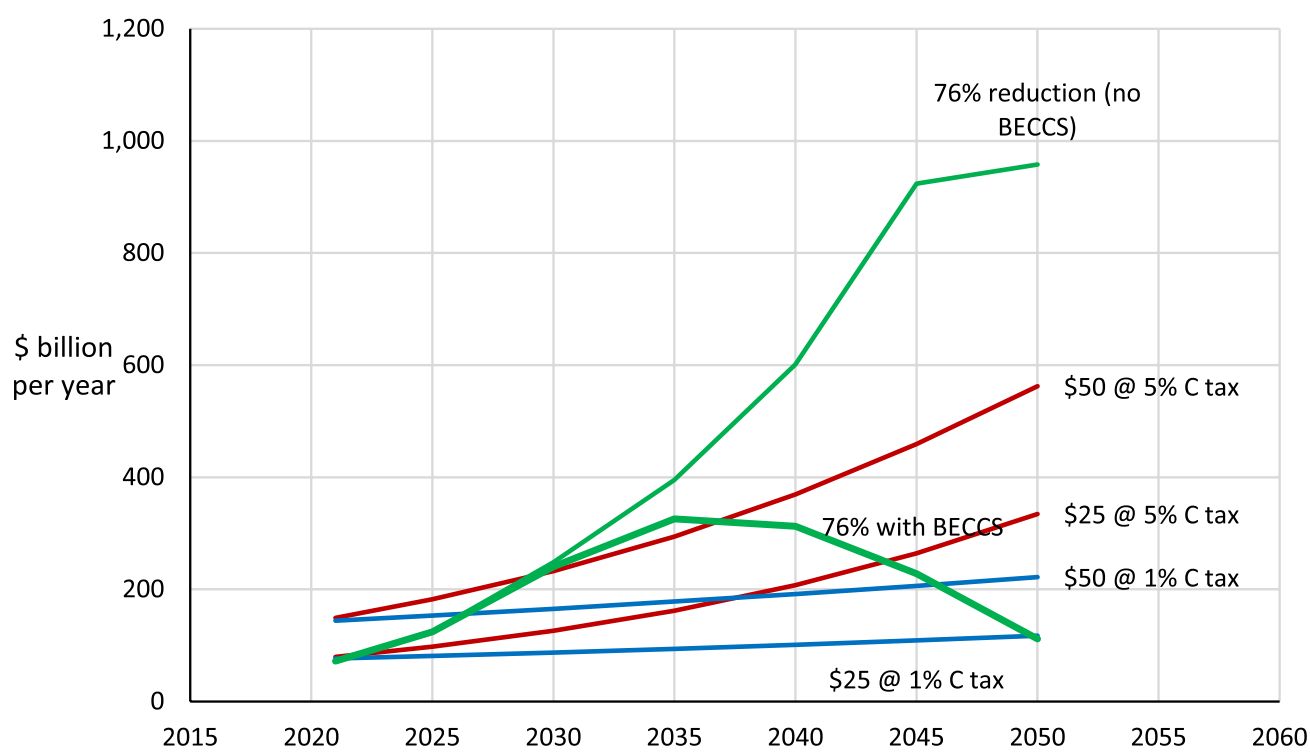

Figure 5. Carbon tax revenues by scenario 
Table 3. Carbon tax revenue as percent of GDP.

\begin{tabular}{lcccccc}
\hline & 2025 & 2030 & 2035 & 2040 & 2045 & 2050 \\
\hline$\$ 25 @ 1 \% \mathrm{C} \operatorname{tax}$ & $0.39 \%$ & $0.38 \%$ & $0.37 \%$ & $0.37 \%$ & $0.37 \%$ & $0.37 \%$ \\
$\$ 50 @ 1 \% \mathrm{C} \operatorname{tax}$ & $0.74 \%$ & $0.72 \%$ & $0.71 \%$ & $0.70 \%$ & $0.69 \%$ & $0.69 \%$ \\
$\$ 25 @ 5 \% \mathrm{C} \operatorname{tax}$ & $0.47 \%$ & $0.55 \%$ & $0.64 \%$ & $0.75 \%$ & $0.89 \%$ & $1.05 \%$ \\
$\$ 50 @ 5 \% \mathrm{tax}$ & $0.88 \%$ & $1.01 \%$ & $1.17 \%$ & $1.34 \%$ & $1.54 \%$ & $1.76 \%$ \\
$76 \%$ reduction with BECCS & $0.60 \%$ & $1.05 \%$ & $1.29 \%$ & $1.14 \%$ & $0.76 \%$ & $0.35 \%$ \\
$76 \%$ reduction (no BECCS) & $0.60 \%$ & $1.08 \%$ & $1.57 \%$ & $2.18 \%$ & $3.10 \%$ & $3.00 \%$ \\
GDP (billions) & $\$ 20,677$ & $\$ 22,964$ & $\$ 25,256$ & $\$ 27,558$ & $\$ 29,814$ & $\$ 31,964$ \\
\hline
\end{tabular}

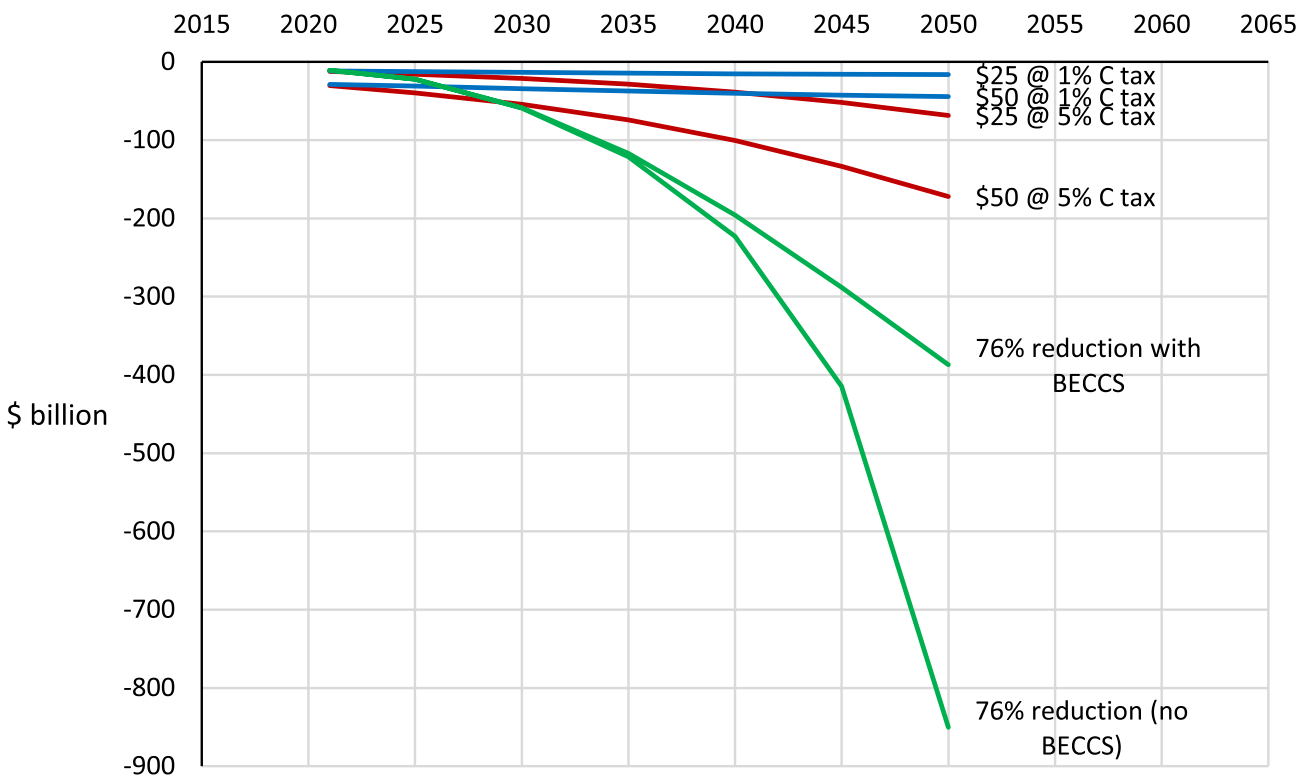

Figure 6. Change in welfare (equivalent variation) by scenario, with lump-sum recycling

The change in consumer welfare for all scenarios, with lump-sum revenue recycling, is shown in Fig. 6. For the deep de-carbonization scenarios, the availability of BECCS reduces the cost of meeting the $76 \%$ reduction target by about half in 2050. BECCS is not available until the $\mathrm{CO}_{2}$ price is high enough to cover the cost of $\mathrm{CO}_{2}$ capture and storage. Welfare costs are growing faster than GDP in most scenarios, so equivalent variation as a percent of GDP grows over time in those scenarios (Table 4).

The welfare cost of a carbon policy includes any increased cost of agricultural production due to increased competition for cropland, and is part of the welfare cost of the $76 \%$ reduction scenario with BECCS shown in Fig. 6. Providing land for an energy 
Table 4. Equivalent variation as percent of GDP.

\begin{tabular}{lcccccc}
\hline & 2025 & 2030 & 2035 & 2040 & 2045 & 2050 \\
\hline$\$ 25 @ 1 \% \mathrm{C} \operatorname{tax}$ & $-0.06 \%$ & $-0.06 \%$ & $-0.06 \%$ & $-0.06 \%$ & $-0.05 \%$ & $-0.05 \%$ \\
$\$ 50 @ 1 \% \mathrm{C} \operatorname{tax}$ & $-0.15 \%$ & $-0.15 \%$ & $-0.15 \%$ & $-0.15 \%$ & $-0.14 \%$ & $-0.14 \%$ \\
$\$ 25 @ 5 \% \mathrm{C}$ tax & $-0.08 \%$ & $-0.09 \%$ & $-0.11 \%$ & $-0.14 \%$ & $-0.17 \%$ & $-0.21 \%$ \\
$\$ 50 @ 5 \% \mathrm{C}$ tax & $-0.19 \%$ & $-0.24 \%$ & $-0.29 \%$ & $-0.37 \%$ & $-0.45 \%$ & $-0.54 \%$ \\
$76 \%$ reduction with BECCS & $-0.11 \%$ & $-0.26 \%$ & $-0.46 \%$ & $-0.71 \%$ & $-0.97 \%$ & $-1.21 \%$ \\
$76 \%$ reduction (no BECCS) & $-0.11 \%$ & $-0.26 \%$ & $-0.48 \%$ & $-0.81 \%$ & $-1.39 \%$ & $-2.66 \%$ \\
GDP (billions) & $\$ 20,677$ & $\$ 22,964$ & $\$ 25,256$ & $\$ 27,558$ & $\$ 29,814$ & $\$ 31,964$ \\
\hline
\end{tabular}

crop shows up in model output through increased food prices and intensification of crop production, which may be offset through increases in agricultural productivity. Another important consideration is the type of land displaced by an energy crop. If forest land is displaced, then additional $\mathrm{CO}_{2}$ is released to the atmosphere, resulting in leakage from a carbon tax program. Analysis of large-scale bioenergy production, and $\mathrm{CO}_{2}$ emissions from land use change, are beyond the scope of EMF-32, but are the focus of a separate study (EMF-33).

\section{Conclusions}

In this paper, we consider the cost side of a climate policy, but not the benefits of reduced carbon dioxide emissions. We have used a CGE model to simulate carbon tax scenarios specified by the EMF-32 steering committee. Within the model, we have shown that the method of tax revenue recycling makes a difference. Either labor-tax, or capital-tax, recycling can reduce the cost of $\mathrm{CO}_{2}$ emissions reductions with a carbon tax. Of the two tax recycling options, reducing capital taxes provides the greater reduction in welfare costs.

This opportunity to reduce costs through tax recycling can vanish, however, with stringent $\mathrm{CO}_{2}$ mitigation targets and a negative emissions technology such as BECCS. In this case, carbon tax revenues are offset by subsidies paid for carbon sequestration.

There remain policy-relevant questions related to BECCS that deserve further study. First, what is the technical and competitive potential for cropland required by BECCS? This is one of the questions addressed by EMF-33, a current study examining global biomass supply and demand. Second, what is the cost and geographical availability of the geologic sequestration resource? How would large-scale adoption of BECCS affect food prices and food security?

There remain challenges for model development. Models used for analysis of alternative climate policies have advanced over the past 25 years to handle both economic and energy flows in a single modeling framework. Food availability and land use have emerged as other important model features. Models will need to simulate the flow of calories from primary agriculture to final consumption as has been done 
already with energy. Further, modelers will need a better understanding of agricultural productivity and how that can change over time, which implies working with researchers in other disciplines such as computational crop modeling.

\section{Acknowledgment}

The views expressed are those of the author and should not be attributed to the Economic Research Service or USDA.

\section{References}

Darwin, R, M Tsigas, J Lewandrowski and A Raneses (1995). World Agriculture and Climate Change: Economic Adaptations, Agricultural Economic Report No. 703, U.S. Department of Agriculture, Economic Research Service.

Edmonds, J, P Luckow, K Calvin, M Wise, J Dooley, P Kyle and L Clarke (2013). Can radiative forcing be limited to $2.6 \mathrm{~W} / \mathrm{m}-2$ without negative emissions from bioenergy and $\mathrm{CO}_{2}$ capture and storage? Climatic Change, 118, 29-43.

Lanz, B and T Rutherford (2016). GTAPINGAMS: Multiregional and small open economy models. Journal of Global Economic Analysis, 1(2), 1-77.

Sands, R, H Förster, C Jones and K Schumacher (2014b). Bio-electricity and Land Use in the Future Agricultural Resources Model (FARM). Climatic Change, 123(3-4), 719-730.

Sands, R, C Jones and E Marshall (2014a). Global Drivers of Agricultural Demand and Supply, ERR-174, U.S. Department of Agriculture, Economic Research Service.

Sands, R, S Malcolm, S Suttles and E Marshall (2017). Dedicated energy crops and competition for agricultural land, ERR-223, U.S. Department of Agriculture, Economic Research Service. 